\title{
Non-Neoplastic Sternal Disorder
}

National Cancer Institute

\section{Source}

National Cancer Institute. Non-Neoplastic Sternal Disorder. NCI Thesaurus. Code C35751.

A non-neoplastic disorder that affects the sternum. 